\title{
Dispnéia provocada por tumor laringeano em gatos no períod o de 1997 a 2007
}

\author{
Laryngeal tumor causing dyspnea in cats evaluated between 1997 and 2007

\begin{abstract}
Katia Barão Corgozinho ${ }^{1}$, Heloisa J usten Moreira de Souza ${ }^{2}$, Ana Maria Reis Ferreira ${ }^{3}$, Simone Carvalho Cunha $^{4} \&$ Cristiane Damico ${ }^{5}$
\end{abstract}

\begin{abstract}
RESUMO
Tumores acometendo a laringe são raros e, geralmente, não têm uma terapia de sucesso. $\mathrm{O}$ exame visual direto da laringe fornece informações importantes para animais suspeitos de doenças laringianas. Este estudo avalia gatos apresentando tumor de laringe no período de dez anos. Nesse período, foram observados somente dois casos com tumores laringianos. Ambos animais apresentaram o histórico de severa e persistente dispnéia, associada a ruído respiratório. A radiografia cervical demonstrou aumento da opacidade dos tecidos moles na laringe em um gato e, no outro, uma massa quase obstruindo totalmente o lúmen. Os gatos foram anestesiados e, a inspeção visual para a intubação, demonstrou a presença de massa que não permitiu a intubação dos gatos. Traqueostomia permanente foi realizada para impedir a oclusão do trato respiratório pela massa. Os donos não permitiram a realização da ressecção da massa e os dois gatos foram eutanasiados, um após o resultado da citologia e o outro após o resultado da histopatologia. Tumores de laringe são incomuns e, geralmente, são malignos em gatos.
\end{abstract}

Decritores: gato, laringe, dispnéia.

\section{ABSTRACT}

Feline larynx tumor appears to be very rare and without successful therapy in cats. Direct visual examination of the larynx using a lighted laryngoscope provides crucial information in patients suspected to have laryngeal diseases. This study reports cats with laryngeal tumor during the period from 1997 to 2007. In this period, only two cats were presented with laryngeal tumor. Both them were presented with history of persistent and severe dyspnea associated with respiratory noise. Cervical radiography was performed and one cat had increased soft tissue opacity to the larynx and the other presented with increased opacity to the larynx almost completely obscuring the lumen. The cats were anesthetized and visual inspection during intubation showed laryngeal mass so that intubation was not possible in both two cats. A permanent tracheostomy was done in both cats to prevent occlusion of the airway by mass. The owners didn't permit the surgery and the two cats were euthanatized, one after the cytological result and the other following the histopathological result. Laryngeal tumors in cats were uncommon and often malignant.

Key words: cats, larynx, dyspnea. 


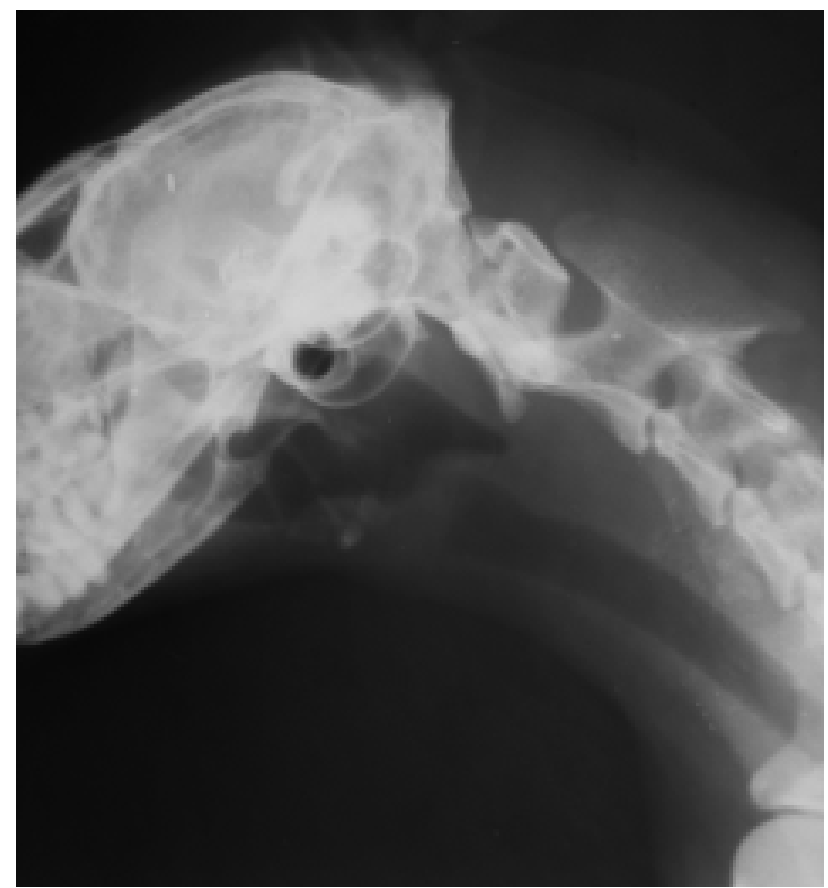

Figura 1A. Radiografias (Gato 1). Radiografia cervical lateral evidenciando um aumento da opacidade da região laringeana.

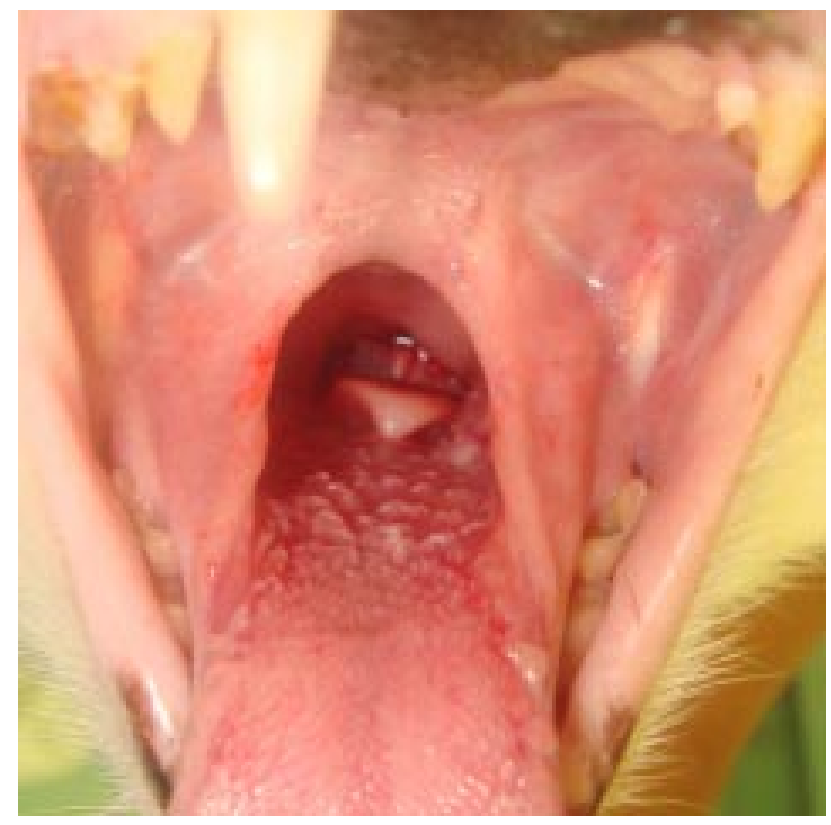

Figura 2. Inspeção da cavidade oral (Gato 1). Observa-se espessamento difuso das cartilagens aritenóides não permitindo a passagem de ar ou do traqueotubo (seta).

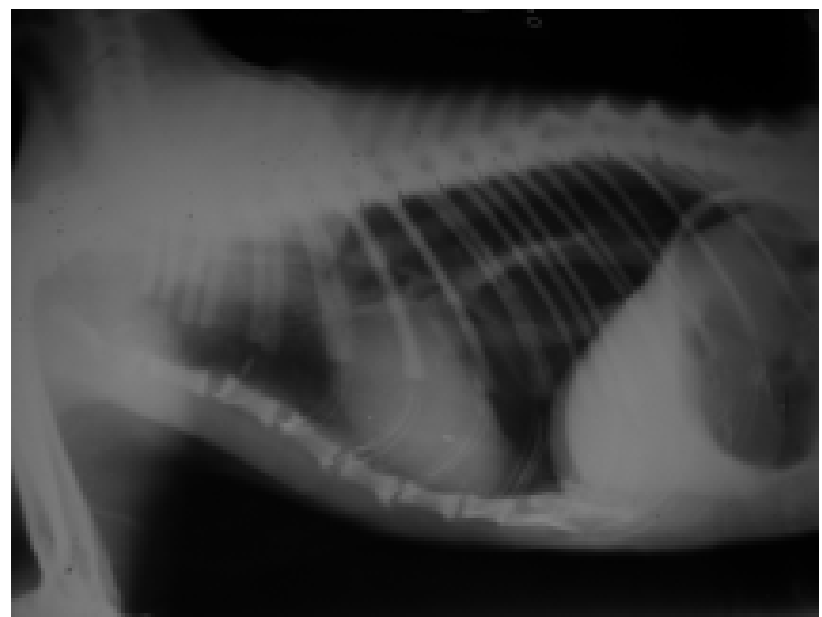

Figura 1B. Radiografias (Gato 1). Radiografia torácica lateral mostrando a hiperinflação pulmonar com deslocamento caudal do diafragma.

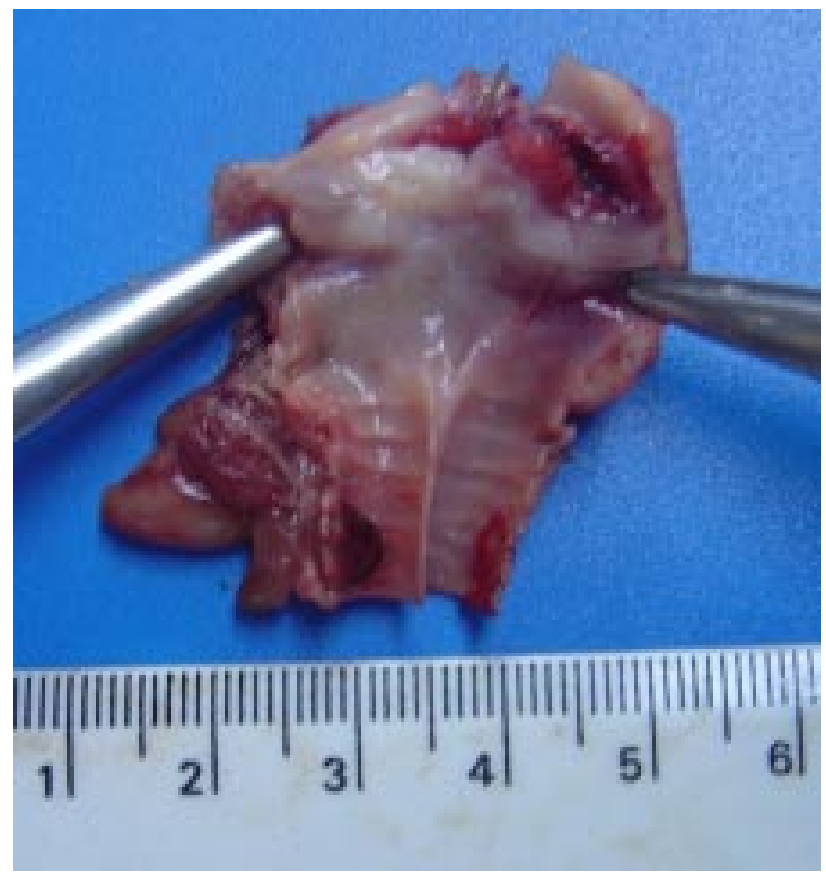

Figura 3A. Neoplasia laringeana (Gato 2). Peça cirúrgica. Observa-se massa de coloração esbranquiçada, na região da laringe, invadindo a traquéia.

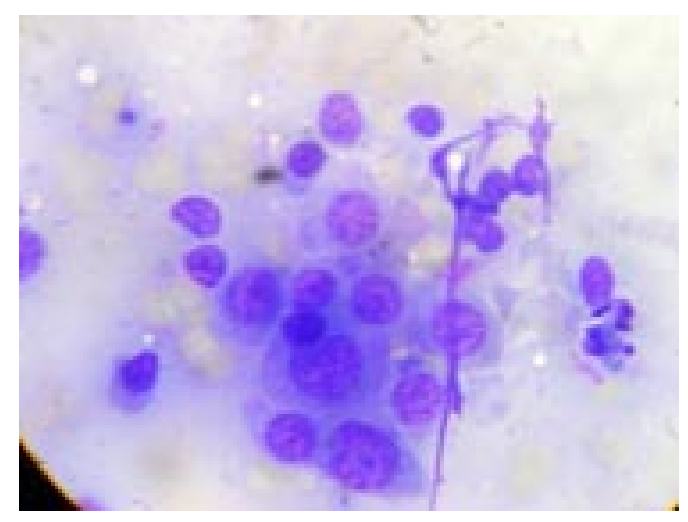

Figura 3B. Neoplasia laringeana (Gato 2). Citologia da massa sugerindo critério de malignidade (anisocitose e nucléolo evidente). 


\section{INTRODUÇÃO}

A incidência de tumores na laringe e traquéia de gatos e cães é rara e, geralmente, esses tumores são malignos [1,2,5,9], acometendo animais de meia idade e idosos. Os sinais clínicos observados são insidiosos e incluem intolerância progressiva a exercício, disfonia, estridor estertor, disfagia, tosse, halitose, hemoptise, hemorragia oral ou ptialismo [1,2,9]. A radiografia simples pode revelar um aumento do formato das estruturas normais ou até a compressão dessas estruturas [9]. A ultra-sonografia pode ser uma ferramenta útil na detecção de tumores e cistos na laringe e traquéia [7]. A tomografia computadorizada e a ressonância magnética permitem avaliar a extensão do comprometimento tumoral [2]. A inspeção da cavidade oral é fundamental para a detecção do local e da extensão do comprometimento [1,9]. O tratamento inclui a retirada cirúrgica, a quimioterapia ou a radioterapia, ou a combinação deles $[1,2,9]$. O prognóstico desses animais é desfavorável [1,9].

O objetivo deste trabalho é relatar gatos com dispnéia, em função de tumores laringeanos, no período de 1997 a 2007.

\section{MATERIAIS E MÉTODOS}

Todos os casos de tumor de laringe foram revisados, em um período de dez anos, na Clínica Veterinária Gatos e Gatos, no Rio de Janeiro. Os dois gatos detectados foram levados ao atendimento pela queixa de dispnéia. O histórico e anamnese desses animais foram obtidos, e o exame clínico foi realizado em cada caso. Radiografias cervicais e torácicas foram realizadas após a aplicação de $0,2 \mathrm{mg} / \mathrm{kg}$ de butorfanol, por via intramuscular. Os animais foram anestesiados com propofol, por via intravenosa, para a inspeção da cavidade com o auxílio do laringoscópio. A amostra da laringe foi coletada em ambos os casos, para o exame histopatológico.

\section{RESULTADOS}

\section{Histórico e sinais clínicos}

A idade dos animais atendidos era treze e nove anos de idade, sendo um macho e uma fêmea, respectivamente. A dispnéia foi aguda no primeiro animal e crônica, de três meses, no outro. A dispnéia inspiratória estava presente em ambos os gatos, além de outros sinais como prostração, emagrecimento e anorexia. Os dois gatos apresentavam dificuldade de deglutição.
Os gatos já tinham recebido cuidados veterinários previamente, sendo tratados pela combinação de antibióticos e corticosteróides, sem melhora clínica evidente do quadro respiratório.

\section{Exame clínico}

Esforço respiratório com estridor foram detectados nos dois casos. A ausculta torácica foi prejudicada pelo ruído respiratório. A palpação da laringe não revelou presença de massa.

\section{Exame radiográfico}

Radiografia cervical revelou espessamento na laringe do gato 1 (Figura 1A), e revelou a presença de uma massa obstruindo o lúmen no aspecto dorsal da laringe, no gato 2 .

A radiografia torácica realizada identificou uma hiperinflação pulmonar, com deslocamento caudal do diafragma, no gato 1.

\section{Inspeção da cavidade com laringoscópio}

Em ambos os casos, foi observado espessamento difuso das cartilagens aritenóides com obstrução da entrada da traquéia, não sendo permitida a intubação traqueal. Os animais foram submetidos a traqueostomia permanente, e um fragmento para biopsia foi retirado da massa.

\section{Avaliação histopatológica}

O gato 1 apresentou dados compatíveis com condrossarcoma laringeano e, o gato 2 , com carcinoma laringeano.

\section{Acompanhamento}

O gato 1, após a traqueostomia, voltou a comer, e não apresentava mais ruído respiratório. $\mathrm{O}$ orifício da traqueostomia foi limpo a cada três horas, em decorrência da excessiva produção de secreção espessada. Dez dias após a traqueostomia, o gato começou a apresentar engasgos, e o proprietário optou pela eutanásia do animal, sem a realização de nenhum tratamento, em decorrência do resultado da histopatologia.

$\mathrm{O}$ gato 2 foi eutanasiado uma hora após a cirurgia, em decorrência do laudo da citologia, sugerindo a presença de critérios de malignidade da massa.

\section{DISCUSSÃO}

O primeiro gato foi atendido com a queixa de dispnéia aguda, apesar de, frequientemente, os animais com tumores laringianos serem atendidos com o histórico de sinais insidiosos [9]. Animais com tumores laringianos 
podem apresentar sinais agudos de obstrução do trato respiratório superior [2], assim como as doenças inflamatórias podem exibir sinais crônicos [8].

Quando o gato apresenta sinais de obstrução do trato respiratório superior, a traqueostomia pode ser realizada para a melhora do quadro clínico. Porém, tem como complicação a produção excessiva de secreção, podendo obstruir o lúmen traqueal e levar à morte do gato, por sufocamento [3, 4]. $\mathrm{O}$ primeiro caso relatado produziu secreção no interior do lúmen traqueal após a traqueostomia, necessitando de limpeza do orifício a cada três horas, para evitar a obliteração da luz traqueal.

Deve-se fazer o diagnóstico diferencial de doenças inflamatórias com as doenças neoplásicas da laringe em gatos através do exame histopatológico, pois processos inflamatórios apresentam os mesmos sinais clínicos de doenças neoplásicas, necessitando também de traqueostomia, para o alívio respiratório imediato, enquanto se espera o resultado [3,4]. Isso é importante para se avaliar o prognóstico, porque, como observado nestes casos, o prognóstico foi desfavorável, pela descoberta de tumores na laringe, fazendo com que os proprietários optassem pela eutanásia dos animais.

A ultra-sonografia da laringe pode ser útil na tentativa de detectar massa na laringe [6,7]. Apesar de não ser realizada a ultra-sonografia da laringe, a inspeção da cavidade oral foi de fundamental importância na comprovação da suspeita de obstrução do trato respiratório superior, assim como em outros relatos [3,5,6], tendo a comprovação da alteração laringiana pela histopatologia.

Em um relato anterior [6], de cinco gatos apresentando tumores laringeanos, quatro animais apresentaram linfoma e um carcinoma de célula escamosa. Em outro relato, de sete gatos, quatro tiveram linfoma, dois carcinoma de célula escamosa e um adenocarcinoma [5]. No presente trabalho, um gato apresentou condrossarcoma e o outro foi acometido por carcinoma, dois tumores incomuns.

\section{CONCLUSÃO}

A incidência de neoplasias na laringe é rara em gatos, sendo dois casos detectados no período de 10 anos de experiência clínica de atendimento a felinos, no Rio de Janeiro. Deve-se diferenciar obstruções inflamatórias do trato superior das neoplásicas através da inspeção da cavidade oral e da histopatologia. Os animais com tumores laringianos, quando chegam ao atendimento clínico ou quando são diagnosticados, estão em estágio avançado da neoplasia, tendo um prognóstico desfavorável.

\section{REFERÊNCIAS}

1 Carlisle C.H., Biery D.N. \& Thrall D.E. 1991. Thracheal and laryngeal tumors in the dog and cat: literature review and 13 additional patients. Veterinary Radiology Radiology and Ultrasound. 32: 229-235.

2 Clifford C.A. \& Sorenmo K.U. 2004. Tumors of the larynx and trachea. In: King L.G. (Ed). Textbook of Respiratory Disease in Dogs and Cats. St Louis:Saunders, pp. 339-345.

3 Costello M.F., Keith D., Hendrick M. \& King L. 2001. Acute upper airway obstruction due to inflammatory laryngeal disease in 5 cats. Journal of Veterinary Emergency and critical care. 11: 205-210.

4 Guenther-Yenke C.L. \& Rozanski E.A. 2007. Tracheostomy in cats: 23 cases (1998-2006). Journal of Feline Medicine and Surgery. 9: 451-457.

5 Rudorf H. \& Barr F. 2002. Echolaryngography in cats. Veterinary Radiology and Ultrasound. 43: 353-357.

6 Rudorf H. \& Brown P. 1998. Ultrasography of laryngeal masses in six cats and one dog. Veterinary Radiology and Ultrasound. 39: 430-434.

7 Rudorf H., Lane J.G., Brown P. \& Mackay A. 1999. Ultrasonographic diagnosis of a laryngeal cyst in a cat. Journal of Small Animal Practice. 40: 275-277.

8 Tasker S., Foster D.J., Corcoran B.M., Whibread T.J. \& Kirby B.M. 1999. Obstructive inflammatory laryngeal disease in three cats. Journal of Feline Medicine and Surgery. 1: 53-59.

9 Wheeldon E.B. \& Amis T.C. 1985. Laryngeal carcinoma in a cat. Journal of America Veterinary Medical Association. 186: 80-81.

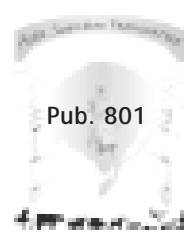

